\title{
ANÁLISE dOS ÁLCOOIS, ÉSTERES E COMPOSTOS CARBONíliCOS EM AMOSTRAS DE ÓLEO FÚSEL
}

\author{
Eduardo R. Pérez, Daniel R. Cardoso e Douglas W. Franco*
}

Departamento de Química e Física Molecular, Instituto de Química de São Carlos, Universidade de São Paulo, CP 780, 13560-970 São Carlos - SP

Recebido em 19/8/99; aceito em 29/8/00

\begin{abstract}
ANALYSIS OF THE ALCOHOLS, ESTERS AND CARBONYL COMPOUNDS IN FUSEL OIL SAMPLES. Analysis of alcohols, esters and carbonyl compounds were performed using HRGC and HPLC techniques in samples of fusel oils from three different Brazilian alcohol distilleries. High content of isoamyl alcohol (390 g.L $\left.\mathrm{L}^{-1}\right)$, isobutyl alcohol (158 g.L $\left.\mathrm{L}^{-1}\right)$, ethyl alcohol $\left(28,4\right.$ g.L $\left.\mathrm{L}^{-1}\right)$, methyl alcohol $(16,6$ g.L $\left.{ }^{-1}\right)$ and n-propyl alcohol $\left(11,9\right.$ g.L $\left.{ }^{-1}\right)$ were found. These compounds represent $77 \pm 8 \%$ of the approximated weight of a liter of fusel oils. The obtained results show the feasibility of using fusel oils as low-cost raw material for the synthesis of chemicals.
\end{abstract}

Keywords: fusel oils; alcohols; esters; carbonyl compounds.

\section{INTRODUÇÃO}

Para países produtores e exportadores de açúcar de cana como Brasil e Cuba é de elevada importância o aproveitamento dos subprodutos: bagaço, óleo fúsel e dióxido de carbono ${ }^{1}$. $\mathrm{O}$ bagaço é empregado como fonte de energia diminuindo o consumo de petróleo nas usinas ${ }^{2}$ ou como matéria prima para a produção de papel e materiais de construção ${ }^{3}$. Entretanto, o óleo fúsel ${ }^{4}$ e o dióxido de carbono ${ }^{5}$ ainda não são devidamente aproveitados.

Óleo fúsel é a fração menos volátil obtida durante o processo de destilação do álcool combustível. A produção de álcool em uma usina de porte médio pode alcançar até 1,5 milhões de litros por dia. A proporção média de óleo fúsel é estimada em 2,5 litros cada 1000 litros de álcool. Assim, torna-se evidente que o volume de óleo fúsel produzido anualmente é considerável, levando-se em conta que a produção de álcool na safra $1997 / 98$ foi de 15,4 bilhões de litros ${ }^{6,7}$. Este trabalho tem como objetivo o estudo qualitativo e quantitativo da composição química do óleo fúsel com vistas à fornecer subsídios para a sua exploração industrial.

\section{PARTE EXPERIMENTAL}

\section{Reagentes}

Os padrões de álcoois, ésteres, áldeídos e cetonas foram sempre de grau analítico (Merck, Aldrich). O álcool etílico e o álcool metílico utilizados foram de grau cromatográfico (Carlo Erba, Mallinckrot). A água utilizada foi previamente destilada e posteriormente desionizada por um sistema Milli-Q (Millipore). $O$ reagente 2,4-dinitrofenilidrazina (Aldrich) foi purificado por três sucessivas recristalizações em metanol.

\section{Amostras}

Foram coletadas amostras de três indústrias produtoras de açúcar e álcool do Estado de São Paulo. As amostras foram codificadas como OF-1, OF-2 e OF-3. Para uma melhor representatividade foram coletadas três amostras de cada produtor em diferentes etapas da safra. Uma das coletas foi uma alíquota proveniente de um tanque de 5000 litros de óleo fúsel

*E-mail: douglas@iqsc.sc.usp.br correspondente ao total acumulado durante toda uma safra. Assim, esta última fornece uma idéia da composição anual média do óleo fúsel produzido pela usina correspondente.

\section{Equipamentos}

Para a análise de álcoois e ésteres empregou-se um Cromatógrafo gasoso HP-5890A equipado com uma coluna HPFFAP $(50 \mathrm{~m} \times 0,2 \mathrm{~mm} \times 0,33 \mu \mathrm{m}$, polietileno glicol modificado) e detector de ionização em chama (FID). A metodologia empregada foi similar aquela utilizada na análise de aguardente ${ }^{8-11}$. A temperatura do detector foi fixada em $250^{\circ} \mathrm{C}$; a do injetor em $250^{\circ} \mathrm{C}$; modo de injeção com divisão na razão $1: 15$; volume de injeção 1,00 uL; fluxo do gás de arraste na coluna $\left(\mathrm{H}_{2}\right): 1 \mathrm{ml} / \mathrm{min}$. Os fluxos dos gases para alimentação do detector foram: $30 \mathrm{ml} / \mathrm{min}$. de $\mathrm{H}_{2}$ e $300 \mathrm{ml} / \mathrm{min}$. de ar sintético. O programa de temperatura utilizado foi: $50^{\circ} \mathrm{C}$ (isotérmico durante 5 min) depois a $2^{\circ} \mathrm{C} / \mathrm{min}$ até $100^{\circ} \mathrm{C}$ (isotérmico durante $3 \mathrm{~min}$ ) depois a $5^{\circ} \mathrm{C} / \mathrm{min}$ até $190^{\circ} \mathrm{C}$ (isotérmico durante $30 \mathrm{~min}$ ) e a $5^{\circ} \mathrm{C} / \mathrm{min}$ até $220^{\circ} \mathrm{C}$ (isotérmico durante $15 \mathrm{~min}$ ). Para a análise álcool etílico, álcool metílico e álcool n-prop empregou-se uma coluna HP-CARBOWAX 20M (50 m x $0,32 \mathrm{~mm}$ x $0,3 \mu \mathrm{m})$ com o seguinte programa de temperatura: $55^{\circ} \mathrm{C}(3 \mathrm{~min})$ a $4^{\circ} \mathrm{C} / \mathrm{min}$ até $80^{\circ} \mathrm{C}$ depois a $6^{\circ} \mathrm{C} / \mathrm{min}$ até $130^{\circ} \mathrm{C}$ depois a $20^{\circ} \mathrm{C} / \mathrm{min}$ até $230^{\circ} \mathrm{C}$. O fluxo do gás de arraste na coluna foi de $1,2 \mathrm{ml} / \mathrm{min}$. As demais condições experimentais empregadas foram as mesmas utilizadas para os outros álcoois.

A análise dos compostos carbonílicos foi efetuada empregando-se um cromatógrafo liquido SHIMADZU LC-10AD equipado com um detector UV-Vis tipo "photodiode array". A separação foi efetuada em uma coluna de fase reversa SUPELCO LC-18 $(25 \mathrm{~cm} \times 4.6 \mathrm{~mm} \times 5 \mu \mathrm{m})$. A fase móvel utilizada foi metanol-água, com gradiente de eluição de $65 \%$ até $85 \%$ de metanol. O comprimento de onda para a detecção dos analitos foi fixada em $365 \mathrm{~nm}$.

\section{Preparo das Soluções Padrões e Curvas de Calibração}

As curvas de calibração para cada um dos álcoois e dos ésteres foram obtidas por diluições das respectivas soluções estoque $(1000 \mathrm{mg} / \mathrm{L})$ em uma solução de álcool etílico-água $(4: 6 \mathrm{v} / \mathrm{v})$. Quando os compostos a serem analisados foram álcool etílico, álcool metílico e álcool n-propílico as curvas de calibração foram preparadas por diluições das respectivas soluções estoque $(1000 \mathrm{mg} / \mathrm{L})$ em álcool isoamilíco. Foram 
Tabela 1. Dados obtidos para as curvas de calibração (álcoois e ésteres: 50, 100, 250, 500 e 1000 mg/L; Acetaldeído: 5, 10, 20, 40 e $60 \mathrm{mg} / \mathrm{L}$; Propionaldeído: 1, 3, 5, 7 e $10 \mathrm{mg} / \mathrm{L}$ )

\begin{tabular}{lccccc}
\hline Composto & $\begin{array}{c}\text { Tempo de } \\
\text { Retenção (min.) }\end{array}$ & $\begin{array}{c}\text { Coeficiente de } \\
\text { regressão linear R }\end{array}$ & $\begin{array}{c}\text { Interseção } \\
\text { A }\end{array}$ & \multicolumn{2}{c}{$\begin{array}{c}\text { Inclinação } \\
\text { B }\end{array}$} \\
\hline Álcool metilíco & 3,08 & 0,9912 & $-0,0324$ & $4,8 \times 10^{-4}$ & $\begin{array}{c}\text { Desvio } \\
\text { padrão S }\end{array}$ \\
Álcool etilíco & 3,30 & 0,9940 & $-0,0277$ & $6,9 \times 10^{-4}$ & 0,0187 \\
Acetato de metila & 3,75 & 0,9981 & $-0,0272$ & $7,0 \times 10^{-4}$ & 0,0106 \\
Álcool n-propilíco & 4,23 & 0,9997 & $-0,0149$ & $2,1 \times 10^{-4}$ & 0,0051 \\
Álcool isobutílico & 11,65 & 0,9934 & $-0,0373$ & $7,7 \times 10^{-4}$ & 0,0440 \\
Acetato de amila & 12,28 & 0,9964 & $-0,0232$ & $7,7 \times 10^{-4}$ & 0,0161 \\
3-pentanol & 13,29 & 0,9940 & $-0,0661$ & $2,8 \times 10^{-3}$ & 0,0773 \\
Álcool n-butílico & 15,02 & 0,9941 & $-0,0254$ & $1,0 \times 10^{-3}$ & 0,0286 \\
Álcool isoamílico & 18,02 & 0,9950 & $-0,0271$ & $1,2 \times 10^{-3}$ & 0,0274 \\
Acetato de hexila & 20,85 & 0,9955 & $-0,0326$ & $1,1 \times 10^{-3}$ & 0,0268 \\
n-octanol & 35,82 & 0,9901 & $-0,0287$ & $1,5 \times 10^{-3}$ & 0,0534 \\
Benzoato de metila & 42,03 & 0,9986 & $-0,0110$ & $1,1 \times 10^{-3}$ & 0,0268 \\
Mentol & 42,40 & 0,9986 & $-0,0138$ & $1,0 \times 10^{-3}$ & 0,0247 \\
Decanol & 46,55 & 0,9844 & $-0,0240$ & $1,3 \times 10^{-3}$ & 0,0609 \\
Dodecanol & 51,70 & 0,9996 & $-0,0110$ & $1,1 \times 10^{-3}$ & 0,0095 \\
Acetaldeído & 9,83 & 0,9995 & 0,6326 & $1,9 \times 10^{-3}$ & 2,3530 \\
Propionaldeído & 23,66 & 0,9946 & $-0,4770$ & $3,8 \times 10^{-3}$ & 1,4580 \\
\hline
\end{tabular}

obtidos cinco pontos de concentração na faixa de 50 a $1000 \mathrm{mg} / \mathrm{L}$, veja-se Tabela 1 . Foi empregado como padrão interno o álcool n-hexílico $(800 \mathrm{mg} / \mathrm{L})$. As curvas de calibração para álcoois e ésteres foram obtidas por regressão linear plotando-se a área do analito/área do padrão interno versus concentração do analito. Os coeficientes de correlação obtidos foram próximos da unidade.

As curvas de calibração para o acetaldeído e o propionaldeído foram preparadas com cinco pontos de concentração na faixa de 5 a $60 \mathrm{mg} / \mathrm{L}$ para acetaldeído e 1 a $10 \mathrm{mg} / \mathrm{L}$ para propionaldeído, a partir das correspondentes 2,4-dinitrofenilhidrazonas. Foi empregada uma mistura metanol/acetonitrila (8:2) como dissolvente. As curvas para os aldeídos foram obtidas por regressão linerar plotando-se a área do analito versus a concentração do analíto, obtendo-se coeficientes de correlação próximos das unidade.

\section{RESULTADOS E DISCUSSÃO}

Na Tabela 1 estão reunidos os valores obtidos para as curvas de calibração dos compostos analisados.

Os álcoois e ésteres foram identificados por sucessivas adições de padrão e pelo respectivo tempo de retenção em diferentes colunas (HP-CARBOWAX 20M E HP-FFAP). Os compostos carbonílicos foram identidicados por comparação do tempo de retenção e sucessivas adições de padrão.

A Tabela 2 resume os resultados provenientes das amostras correspondentes a diferentes etapas da safra de 1997 / 98, de três usinas produtoras de álcool. Observa-se através destes resultados que os álcoois isoamilíco e isobutilíco são os compostos majoritários. Foram encontrados baixos teores médios dos ésteres e aldeídos detectados nas amostras analisadas o que não descarta a possibilidade da sua exploração futura, empregando tecnologias convenientes.

A Tabela 3 a seguir resume os teores médios para os principais compostos nas amostras de óleo fúsel estudadas mostrando que os teores médios dos álcoois isoamilíco (390,0 g.. $\left.\mathrm{L}^{-1}\right)$ e isobutilíco $\left(158,0\right.$ g. $\left.\mathrm{L}^{-1}\right)$ nas diversas amostras são da mesma ordem de grandeza. Estes componentes possuem reconhecida importância dadas as suas aplicações como reagentes em sínteses
Tabela 2. Teores médios de álcoois, ésteres e aldeídos em amostras de óleo fúsel. Concentração média $\left(\mathrm{g} . \mathrm{L}^{-1}\right)$ de 3 series de amostras para cada usina.

\begin{tabular}{lccc}
\hline Composto & OF-1 & OF-2 & OF-3 \\
\hline Álcool metilíco & 26,9 & 17,7 & 5,0 \\
Álcool etilíco & 46,9 & 12,0 & 26,4 \\
Álcool n-propilíco & 14,5 & 6,5 & 14,6 \\
Álcool isoamílico & 380 & 367 & 425 \\
Álcool isobutílico & 133 & 140 & 201 \\
Acetato de metila & $\mathrm{ND}$ & $8,7 \times 10^{-4}$ & $\mathrm{ND}$ \\
Acetato de amila & $3,7 \times 10^{-4}$ & $\mathrm{ND}$ & $\mathrm{ND}$ \\
3-pentanol & $1,1 \times 10^{-4}$ & $\mathrm{ND}$ & $8,3 \times 10^{-5}$ \\
Álcool n-butílico & $2,7 \times 10^{-3}$ & $2,3 \times 10^{-3}$ & $6,0 \times 10^{-4}$ \\
Acetato de hexila & $2,3 \times 10^{-4}$ & $2,5 \times 10^{-4}$ & $5,8 \times 10^{-4}$ \\
n-octanol & $1,4 \times 10^{-4}$ & $9,8 \times 10^{-4}$ & $\mathrm{ND}$ \\
n-decanol & $1,2 \times 10^{-4}$ & $\mathrm{ND}$ & $9,0 \times 10^{-5}$ \\
Álcool n-amílico & $1,7 \times 10^{-3}$ & $2,1 \times 10^{-3}$ & $3,1 \times 10^{-3}$ \\
Formiato de etila & $1,1 \times 10^{-4}$ & $\mathrm{ND}$ & $9,4 \times 10^{-4}$ \\
Álcool 2-butílico & $1,3 \times 10^{-4}$ & $2,0 \times 10^{-3}$ & $3,0 \times 10^{-3}$ \\
Benzoato de metila & $1,4 \times 10^{-3}$ & $1,6 \times 10^{-3}$ & $9,3 \times 10^{-3}$ \\
Acetaldeído & $1,2 \times 10^{-2}$ & $1,0 \times 10^{-2}$ & $5,2 \times 10^{-3}$ \\
Propionaldeído & $1,9 \times 10^{-3}$ & $3,1 \times 10^{-3}$ & $2,8 \times 10^{-3}$ \\
\hline
\end{tabular}

ND: não detectados.

orgânicas ${ }^{12-18}$ e como solventes de extração nas analises de compostos de interesse farmacológico ${ }^{19,20}$. Seus derivados, ésteres, têm grande utilidade nas indústrias de plástico e perfumaria.

A Tabela 4 reúne os álcoois que constituem $77 \pm 8 \%$ da massa média de um litro de óleo fúsel. O álcool isoamilíco apresenta a maior contribuição a esta porcentagem.

Assim elevados teores dos álcoois isoamilíco e isobutilíco (390 e 158 gramas, respectivamente por litro do óleo fúsel), o baixo preço comercial do óleo fúsel (R\$ 0,30 por litro) e seu 
Tabela 3. Teores médios (g. $\left.\mathrm{L}^{-1}\right)$ dos álcoois majoritários nas amostras analisadas. ( \pm desvio padrão).

\begin{tabular}{lcccc}
\hline Composto & OF-1 & OF-2 & OF-3 & Média \\
\hline Álcool metilíco & $26,9( \pm 1,1)$ & $17,7( \pm 0,9)$ & $5,0( \pm 0,8)$ & $16,6( \pm 8,9)$ \\
Älcool etilíco & $46,8( \pm 0,8)$ & $12,0( \pm 0,7)$ & $26,4( \pm 1,0)$ & $28,4( \pm 17,8)$ \\
Álcool n-propilíco & $14,5( \pm 2,5)$ & $6,5( \pm 1,3)$ & $14,6( \pm 2,0)$ & $11,9( \pm 4,7)$ \\
Álcool isoamilíco & $380( \pm 8)$ & $367( \pm 7)$ & $425( \pm 12)$ & $390( \pm 48)$ \\
Álcool isobutilíco & $133( \pm 7)$ & $140( \pm 4)$ & $201( \pm 6)$ & $158( \pm 59)$ \\
\hline
\end{tabular}

Tabela 4. Porcentagens dos álcoois majoritários nas amostras de óleo fúsel analisadas.

\begin{tabular}{lcccc}
\hline Composto & $\begin{array}{c}\text { Concentração } \\
\text { média }\left(\mathrm{g} . \mathrm{L}^{-1}\right)\end{array}$ & $\begin{array}{c}\text { OF-1 } \\
\left(812 \mathrm{~g} . \mathrm{L}^{-1}\right)\end{array}$ & $\begin{array}{c}\text { OF-2 } \\
\left(786 \mathrm{~g} . \mathrm{L}^{-1}\right)\end{array}$ & $\begin{array}{c}\text { OF-3 } \\
\left(788 \mathrm{~g} . \mathrm{L}^{-1}\right)\end{array}$ \\
\hline Álcool metilíco & 16,6 & $3,3 \%$ & $2,3 \%$ & $0,7 \%$ \\
Álcool etilíco & 28,4 & $5,7 \%$ & $1,5 \%$ & $3,3 \%$ \\
Álcool n-propilíco & 11,9 & $1,8 \%$ & $0,8 \%$ & $1,8 \%$ \\
Álcool isobutilíco & 158 & $16,4 \%$ & $17,8 \%$ & $25,5 \%$ \\
Álcool isoamilíco & 390 & $46,8 \%$ & $46,6 \%$ & $54,0 \%$ \\
Totais & 705 & $74,0 \%$ & $69,0 \%$ & $85,3 \%$ \\
\hline
\end{tabular}

elevado volume de produção por safra (350 milhões de litros na safra 1997-98), são fatores que devem estimular propostas de desenvolvimento de tecnologia para a sua exploração industrial. Estudos de algumas destas propostas encontram-se em desenvolvimento em nosso Laboratório.

\section{AGRADECIMENTOS}

Os autores agradecem a FAPESP, CNPq e CAPES pelos auxílios financeiros e bolsas concedidas. As usinas do Estado de São Paulo: Colosso, São José do grupo Zillo-Lorenzetti e Malosso pela doação das amostras.

\section{REFERÊNCIAS}

1. Clarke, M.; Edye, L.; ACS Sym. Ser. 1996, 647, 229.

2. Dados obtidos durante uma visita realizada na usina São José do grupo Zillo-Lorenzetti, novembro de 1998, (Comunicação particular).

3. Dados do Ministério da Indústria Açúcareira de Cuba (MINAZ), outubro de 1998 (Comunicação particular).

4. Cooperativa dos Produtores de Cana, Açúcar e Álcool do Estado de São Paulo Ltda. - COPERSUCAR., V Seminário de Tecnologia Industrial, São Paulo, Editoração Eletrônica; Digital Art Computação Gráfica S/C Ltda. 1993.

5. Aresta, M.; Quim. Nova 1999, 22, 269.
6. Clark, W. C.; Ed. Carbon Dioxide Review, 1992; Clarendon Press; Oxford, U. K., 1982, 303.

7. Oman, H.; CHEMTECH 1988, 116.

8. Bezerra, C. W. B.; Nascimento, R. F.; Cerroni, J. L.; Lima Neto, B. S.; Franco, D. W.; Reunião Anual da SBQ, Caxambu - MG, 1994.

9. Bezerra, C. W. B.; Nascimento, R. F.; Furuya, S. M. B.; Cerroni, J. L.; Lima Neto, B. S.; Franco, D. W.; Reunião Anual da $S B Q$, Caxambu - MG, 1995.

10. Lanças, F. M.; Galhiane, M. S.; Bol. Soc. Chil. Quim. 1993, 38, 177.

11. Bezarra, C. W.; Dissertação de Mestrado, IQSC-USP, São Carlos, SP, 1995.

12. Catálogo SIGMA de reagentes químicos, 1998.

13. Ogonowski, J.; Sikora, E.; Przem Chem. 1996, 75, 135.

14. Lietti, L.; Sun, Q.; Herman, R. G.; Catal. Today 1996, 27, 151.

15. Vaze, A. S.; Sawant, S. B.; Pangarkar, V. G.; J Appl. Electrochem. 1997, 27, 584.

16. Mitra, A.; Subramanian, S.; Das, D.; Appl. Catal. A-Gen. 1997, 153, 233.

17. Sasaki, Y., Chem. Lett. 1996, 9, 825.

18. Kuroda, Oi. S.; Matsuno, Y. S.; Nippon Kagaku Kaishi $1993,8,985$.

19. Garcia, M. A.; Aramayona, J. J.; Bregante M. A.; J. Chromatogr. B 1997, 693, 377.

20. Liaw, W. J.; Ho, S. T.; Wang J. J.; Hu, O. Y. P.; Li, J. H.; J. Chromatogr. B 1998, 714, 237. 